\title{
Оцінка розмірних і якісних параметрів роботи горизонтального дискового дозатора
}

\author{
М.П.Артьомов, О.Д. Калюжний ${ }^{1}$, О.А. Романашенко ${ }^{2}$, І.О. Колодяжний \\ Харківський національний технічний університет сільського господарства \\ імені Петра Василенка(м. Харків, Україна) \\ email:1 aleksandrkaluzhnij@gmail.com; ${ }^{2}$ romanashenko.a@gmail.com; \\ ORCID: ${ }^{1}$ 0000-0001-5587-6606; ${ }^{2}$ 0000-0002-0857-628
}

\begin{abstract}
Велика нерівномірність розсіву добрив відцентровими розкидачами пояснюється наступними причинами. По-перше це прояв технічних особливостей розкидання добрив відцентровим органом. По-друга це вплив фрізико-механічних властивостей сипких добрив і третя причина велика неточність подання добрив через дозуюче вікно пристрою на розкидаючий диск Встановлено, що відцентровим дисковим розкидачем сипких мінеральних добрив властива природна нерівномірність розподілення добрив по поверхні поля, яка значно посилюється сегрегацією часток добрив на стадії їх польоту. Так досягти підвищення якості розподілу можна за рахунок істотного зменшення ширини розкидання добрив кожним окремим диском, зменшивши його діаметра. 3 метою покращення якості розсіву добрив запропоновано багатодисковий пристрій для розсіву мінеральних добрив по поверхні поля. Пропонується пристрій виконати у вигляді самостійних, функціонально незалежних модулів. Кожен модуль складається з трьох незалежних блоків: місткості для добрив з мішалкою; горизонтального дискового дозатора з калібрувальними отворами; горизонтальної тарілки розкидача. Кожен з блоків забезпечений індивідуальним електроприводом. Таке виконання дає можливість здійснювати регулювання дозування добрив на розкидаючу тарілку і дальності розкиду добрив, шляхом індивідуальної установки певного числа обертів обертання диска дозатора і тарілки розкиду добрив. Дана компонування не обмежувати їх число та місцем закріплення на рамі, а ширина захопленню агрегату буде регламентуватися тільки їх кількістю і дальністю розкиду добрив кожним індивідуальним блоком. У результаті досліджень макетного зразка дозатора з активним примусово- порційним дозуванням сипких мінеральних добрив отримана його задовільна роботоздатність. Але дослідження показали, що величина заповнення отворів диска залежить від обертів його обертання і від розмірних параметрів вікон завантаження і вивантаження, а також наявності бордюру розташованого у кінці завантажувального вікна. Бордюр запобігає зрушенню шарів добрива відносно один до одного і поверхні диска, що обертає, тим самим покращуючи заповнення отворів добривами.
\end{abstract}

Ключові слова : мінеральні добрива, диск дозування, розкидаюча тарілка, рівномірність подання, обертів, калібрувальний отвір, вікно завантаження, вікно вивантаження.

Метою роботи була експериментальна оцінка продуктивності активного дискового дозатора сипких мінеральних добрив від розмірних параметрів вікна завантаження і вікна вивантаження добрив і частоти обертів диска дозатора.

Стан питання Запропонований пристрій (Рис.1) виконує активну, примусово-порційну дозовану подачу комірками диска 3 , який обертається з невеликою коловою швидкістю. При проходженні над отвором днища бункера 1 комірки наповнюються сипкими мінеральними добривами. Обертаючись диск 3 комірками переносить їх в комірках до отвору нижнього нерухомого диску 4. Цей отвір розміщено над подавальним лотком 5 , через який добрива попадають на тарілку, яка їх розкидає.

Як було встановлено, в процесі лабораторних досліджень, на величину продуктивності окрім частоти обертів, розміру і форми комірок, впливає ще і розмірні параметри (довжина і ширина) вікна завантаження і вікна вивантаження добрив. Оцінка впливу розмірних параметрів вікон робилася шляхом встановлення їх різних величин (таблиця 1) і постійних чисельних і об'ємних значень отворів.

При розмірі вікон 35х17 мм і оборотах від 45 до 90 об./хв. продуктивність збільшувалася від 232 до 303гр./мин. Подальше підвищення частоти до значення 130 об./хв. призводило до зменшення продуктивності до 90 гр./мин.

Встановлення вікна завантаження розміром 60x17 мм з бордюром заввишки 10 мм з збереженням вікна вивантаження в колишніх розмірах $35 \times 17$ мм при частоті від 38 до 90 об/хв. збільшувало продуктивність від 233 до 363 гр./хв. Подальше збільшення до значення 130 об/хв. призводило до незначного зниження продуктивності до 360 гр./хв. 


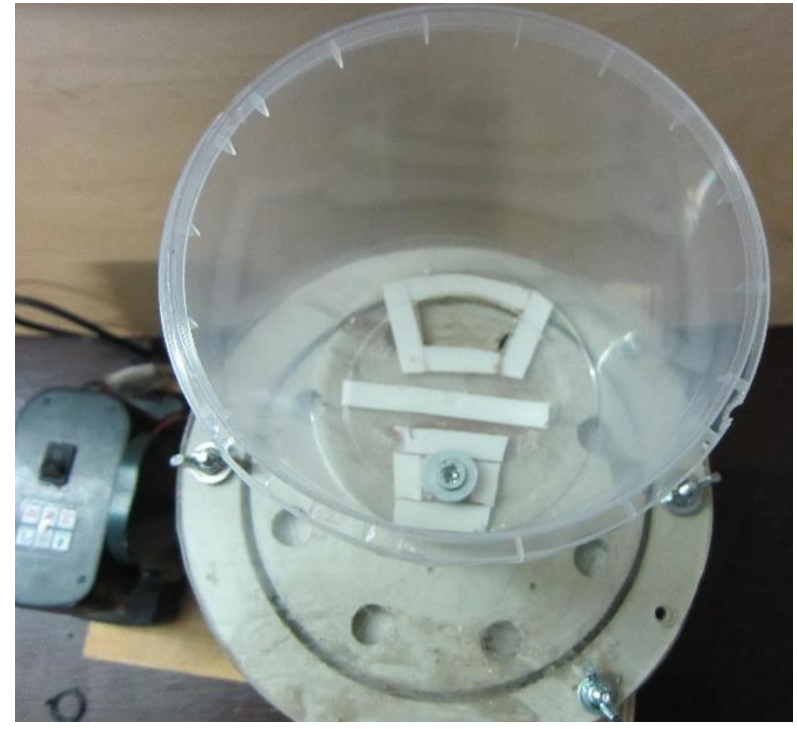

a

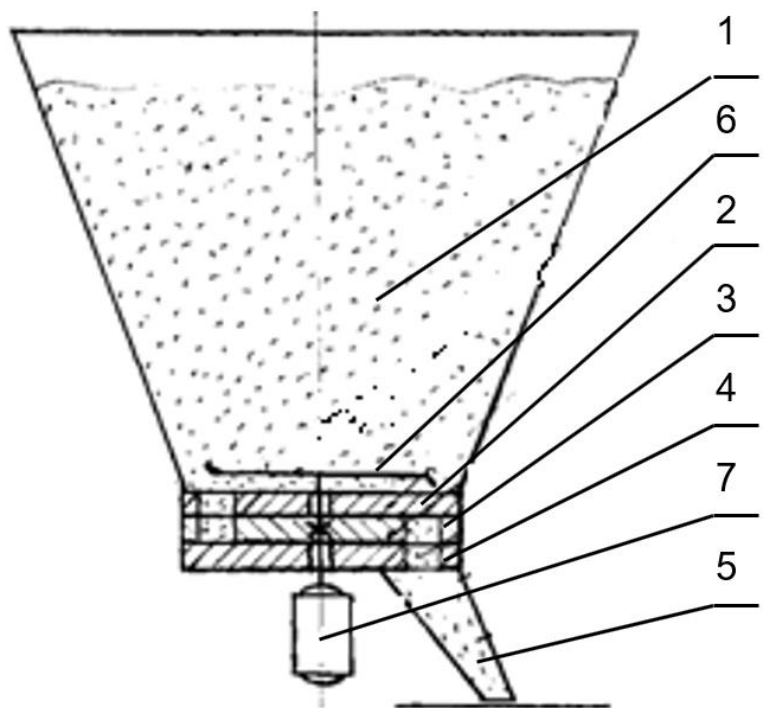

6

Рис. 1. Активний дозатор сипучих мінеральних добрив:

а) - загальний вид лабораторного пристрою; б) - схема будови

Таблиця 1.Залежність продуктивності дозатора від розмірів завантажувального і вивантажувального вікна

\begin{tabular}{|c|c|c|c|c|c|c|c|c|c|}
\hline & № & $\begin{array}{l}\text { 当 } \\
. \frac{9}{0} \\
0 \\
0 \\
\frac{0}{0} \\
\circ \\
\text { ○ } \\
\frac{0}{J}\end{array}$ & 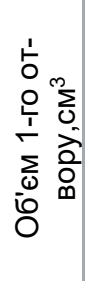 & 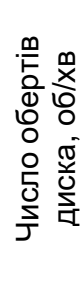 & 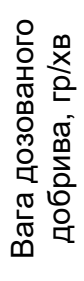 & 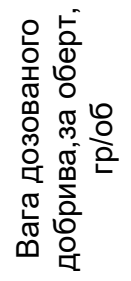 & 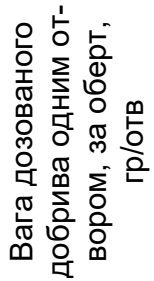 & $\begin{array}{l}\text { Розмір завантажу- } \\
\text { вального вікна,мм. }\end{array}$ & $\begin{array}{c}\text { Розмір вивантаж- } \\
\text { ного вікна,мм. }\end{array}$ \\
\hline & 1 & 2 & 3 & 4 & 5 & 6 & 7 & 8 & 9 \\
\hline & 1 & & & 45 & 232 & 5,16 & 0,64 & $35 \times 17$ & $35 \times 17$ \\
\hline & 2 & & & 60 & 280 & 4,67 & 0,58 & & \\
\hline & 3 & & & 72 & 296 & 4,11 & 0,51 & & \\
\hline 1 & 4 & 8 & 1 & 92 & 303 & 3,29 & 0,41 & & \\
\hline & 5 & & & 104 & 250 & 2,40 & 0,30 & & \\
\hline & 6 & & & 120 & 218 & 1,81 & 0,23 & & \\
\hline & 7 & & & 130 & 195 & 1,5 & 0,19 & & \\
\hline 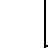 & 1 & & & 38 & 233 & 6,06 & 0,75 & $\times 17$ & K17 \\
\hline & 2 & & & 54 & 299 & 5,53 & 0,69 & & \\
\hline & 3 & & & 67 & 294 & 4,37 & 0,54 & & \\
\hline 2 & 4 & 8 & 1 & 74 & 334 & 4,51 & 0,56 & & \\
\hline & 5 & & & 90 & 363 & 3,97 & 0,49 & & \\
\hline & 6 & & & 102 & 360 & 3,52 & 0,44 & & \\
\hline & 7 & & & 130 & 360 & 2,78 & 0,34 & & \\
\hline & 1 & & & 40 & 237 & 5,87 & 0,73 & $60 \times 17$ & $\times 17$ \\
\hline & 2 & & & 58 & 332 & 5,75 & 0,719 & & \\
\hline & 3 & & & 68 & 380 & 5,56 & 0,69 & & \\
\hline 3 & 4 & 8 & 1 & 88 & 470 & 5,34 & 0,66 & & \\
\hline & 5 & & & 108 & 510 & 4,72 & 0,59 & & \\
\hline & 6 & & & 114 & 550 & 4,82 & 0,60 & & \\
\hline & 7 & & & 142 & 540 & 3,80 & 0,47 & & \\
\hline
\end{tabular}

Інженерія природокористування, 2020, №317), с. 76 - 80 Engineering of nature management, 2020, \#3(17), p. 76 - 80 
При встановленні вікна завантаження розміром 60х17 мм з бордюром заввишки 10 мм і вікна вивантаження 60х17 мм з зміною частоти від 40 до 142 об/хв. Призводило до зростання продуктивності від 237 до 540 гр./мин.

За даними (таблиця.1) побудовані графіки (рис.2, рис.3, рис.4). Аналіз показує, що найбільша продуктивність і краща заповнюваність отворів дозуючого диска, що калібруються, відбувається, коли розміри вікна завантаження і вікна вивантаження мають величини $60 \times 17$ мм. а у кінці вікна завантаження встановлений бордюр заввишки 10 мм .Ці розміри відповідають співвідношенню розміру вікон до діаметру калібрувальному отвору (діаметр отвору складає 13 мм) як 4,62x1,30. Збільшення числа обертання дозуючого диска понад 100 об/хв. погіршує заповнюванню отворів гранулами добрив. Це спостерігається при усіх розмірних параметрах вікон (рис.3, рис.4). Але як видно 3 кривої 3 (рис3. і рис.4) краща заповнювання отворів диска обмежене розмірами вікон 60х17мм. і частотою від 40 до 100 об/хв. Це число обертів дозволяє міняти величину продуктивності від 237 до 500 гр./мин., що відповідає зміні продуктивності в 2,10 разу або на 110 відсотків.

Якість роботи дозатора оцінювалась рівномірністі його продуктивності. Оцінка проводилася методом математичної статистики. Визначалися: середнє значення маси добрив - gср; середньоквадратичне відхилення - бср; нерівномірність розподілу добрив - Нк (коефіцієнт варіації); помилка середнього арифметичного значення - $\lambda$; відносна помилка середнього арифметичного значення - р. Отримані дані показують (таблиця, 2), що зміна частоти оборотів від 38 до 142 об/хв. змінює середнє значення маси добрив (gcp. ) від 218 до 550 гр./мин.; середньоквадратичне відхилення (бср ) від 5 до 40; нерівномірність розподілу добрив Нк (коефіцієнт варіації) від 0,010 до 0,160; помилка середнього арифметичного значення ( $\lambda$ ) від 2,236 до 31,306; відносна помилка середнього арифметичного значення ( $\rho)$ від 0,004 до 0,071. Для прийнятих розмірів - вікна завантаження 60х17 мм з бордюром заввишки 10 мм, вікна вивантаження 60х17 мм при обертах від 40 до 100 об/хв. якість роботи знаходиться в наступних межах: середнє значення маси добрив (gcp) від 236 до 510 гр./мин.; середньоквадратичне відхилення (бср ) від 5 до 18; нерівномірність розподілу добрив Нк (коефіцієнт варіації) від 0,010 до 0,120; помилка середнього арифметичного значення $(\lambda)$ від 2,23 до 13,417; відносна помилка середнього арифметичного значення ( $\rho)$ від 0,004 до 0,034. Отримані значення відповідають вимогам до облаштувань цього типу.

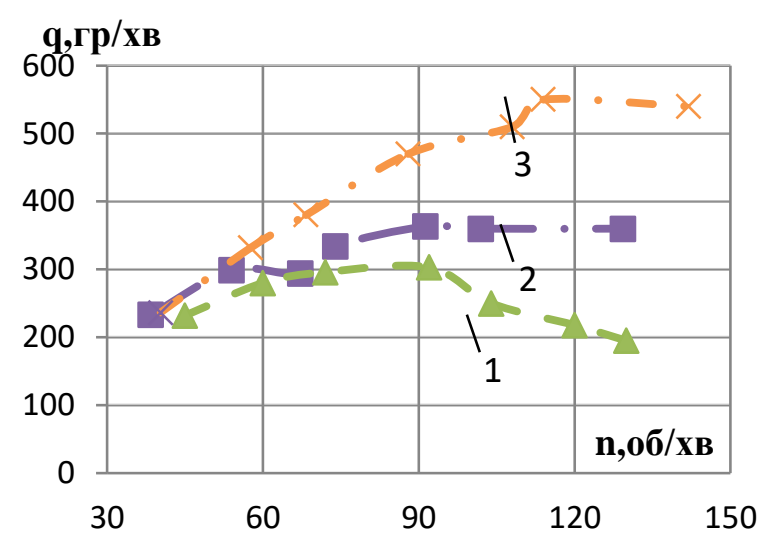

Рис. 2. Продуктивність диска за одну хвилину залежно від розмірів вікон.

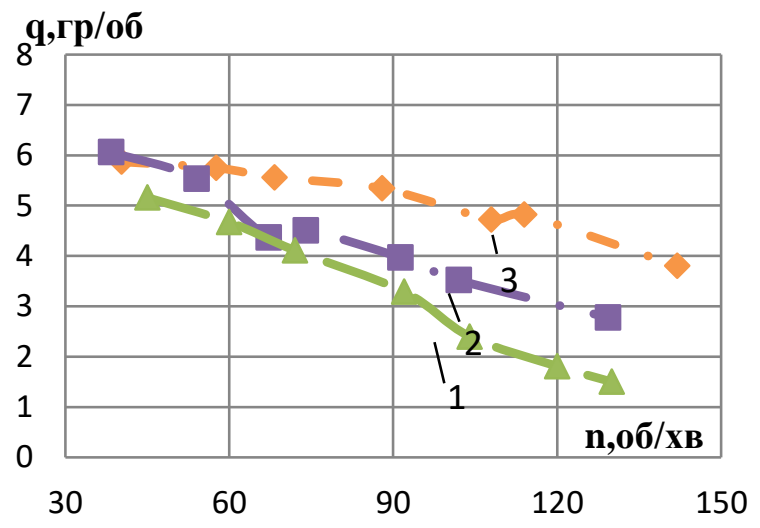

Рис.3. Продуктивність за один оберт диска залежно від розміру вікон.

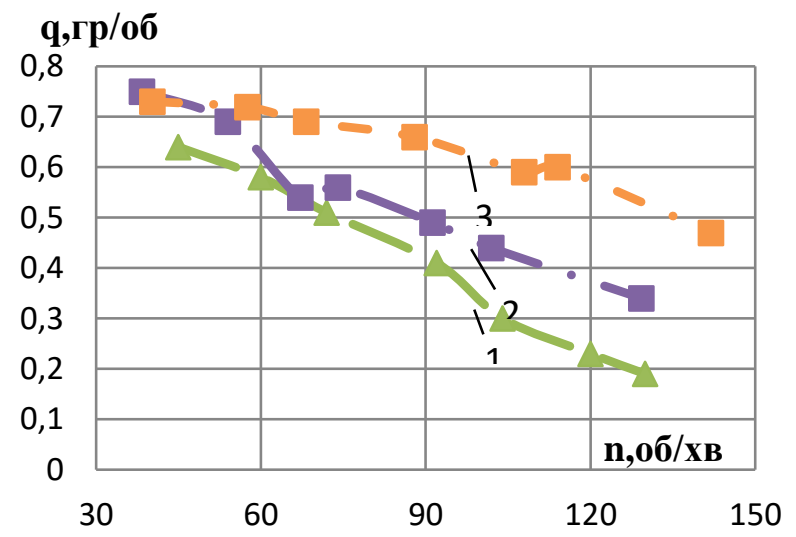

Рис.4. Продуктивність одного отвору за один оберт залежно від розміру вікон.

\section{Висновки.}

1.Бажанна продуктивність забезпечується вікном завантаження розміром 60х17мм. зі встановленим у кінці його бордюром і вікном вивантаження розміром 60х17мм., що відповідає відношенню розміру вікон до діаметру калібрувальному отвору (діаметр отвору складає 13 мм) як $4,62 \times 1,30$. 
Таблица 2. Якісні показники роботи дозатора

\begin{tabular}{|c|c|c|c|c|c|c|}
\hline № & 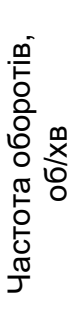 & 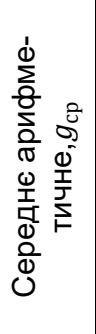 & 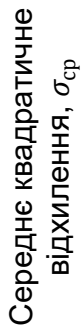 & 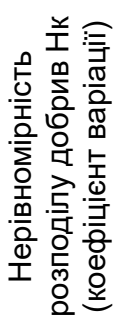 & 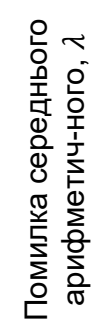 & 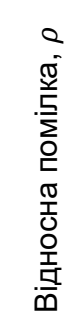 \\
\hline & 1 & 2 & 3 & 4 & 5 & 6 \\
\hline \multirow{7}{*}{1} & 45 & 232 & 8 & 0,034 & 3,578 & 0,015 \\
\hline & 60 & 280 & 5 & 0,018 & 2,236 & 0,008 \\
\hline & 72 & 296 & 8 & 0,027 & 3,578 & 0,012 \\
\hline & 92 & 303 & 29 & 0,096 & 12,97 & 0,043 \\
\hline & 104 & 250 & 40 & 0,160 & 17,89 & 0,071 \\
\hline & 120 & 218 & 19 & 0,087 & 8,497 & 0,039 \\
\hline & 130 & 195 & 30 & 0,154 & 13,417 & 0,069 \\
\hline \multirow{7}{*}{2} & 38 & 233 & 18 & 0,077 & 8,05 & 0,034 \\
\hline & 54 & 299 & 9 & 0,030 & 4,025 & 0,013 \\
\hline & 67 & 294 & 24 & 0,082 & 10,733 & 0,036 \\
\hline & 74 & 334 & 28 & 0,084 & 12,522 & 0,037 \\
\hline & 91 & 363,2 & 26,8 & 0,074 & 11,985 & 0.033 \\
\hline & 102 & 360 & 20 & 0,055 & 8,944 & 0,025 \\
\hline & 129 & 360 & 25 & 0,069 & 11,18 & 0,031 \\
\hline \multirow{7}{*}{3} & 40 & 236 & 18 & 0,077 & 8,14 & 0,034 \\
\hline & 57 & 331 & 18 & 0,057 & 8,408 & 0,025 \\
\hline & 68 & 380 & 5 & 0,013 & 2,23 & 0,006 \\
\hline & 88 & 470 & 30 & 0,063 & 13,417 & 0,028 \\
\hline & 108 & 510 & 5 & 0,010 & 2,236 & 0,004 \\
\hline & 114 & 550 & 70 & 0,120 & 31,306 & 0,057 \\
\hline & 142 & 540 & 5 & 0,009 & 2,236 & 0,004 \\
\hline
\end{tabular}

2. Зростання продуктивності визначається обертанням дозуючого диска від 40 до 100 обертів в хвилину, що дозволяє регулювати продуктивність від 237 до 500 гр./мин., що відповідає величині в 2,10 разу.
3.Нерівномірність розподілу добрив (Нк.в. коефріцієнт варіації) знаходиться в межах від 0,010 до 0,120.

\section{Література:}

1. Бакум, М. В. и др. (2008) Сільськогосподарські машини. ХНТУСГ, навч. посіб. ХНТУСГ. Харків. С. 288

2. Назаров, С. А. и др. (1997) Рівномірний розподіл тукових сумішей. Колос, Техніка в сільському господарстві. Колос. Москва. сс. 27-30

3. Мельник, В. І. и др. (2018) ‘Багатодисковий Розкидач мінеральних добрив з дозуюче-розкідаючім модулями', Науковий журнал «інженерія природокористування», 1(9), сс. 96-99.

4. Мельник, В. І. и др. (2019) ‘Експериментальне дослідження активного дискового дозатора сипучих мінеральних добрив', Науковий журнал «Механізація Сільськогосподарського виробництва», 199, с. 218.

\section{Reference:}

1. Bakum, M.V. et al. (2008) Sllskogospodarskl mashini. HNTUSG, navch. poslb. HNTUSG. Harklv. p. 288

2. Nazarov, S. A. et al. (1997) Rlvnomlrniy rozpodll tukovih sumlshey. Kolos, Tehnlka $v$ sllskomu gospodarstvl. Kolos. Moskva. pp. 27-30

3. Melnik, V.I. et al. (2018) 'Bagatodlskovly Rozkidach mlneralnih dobriv $z$ dozuyucherozkldayuchlml modulyami', Naukoviy zhurnal «Inzhenerlya prirodokoristuvannya», 1(9), pp. 96-99.

4. Melnik, V. I. et al. (2019) 'Eksperimentalne doslldzhennya aktivnogo diskovogo dozatora sipuchih mlneralnih dobriv', Naukoviy zhurnal «Mehanlzatslya Sllskogospodarskogo virobnitstva», 199 , p. 218

\section{Аннотация}

\section{Оценка размерных и качественных параметров работы горизонтального дискового дозатора}

\section{Н.П.Артёмов, А.Д. Калюжный, А.А. Романашенко, И.А. Колодяжный}

Большая неравномерность рассева удобрений центробежными разбрасывателями объясняется следующими причинами. Во-первых это проявление технических особенностей разбрасывания удобрений центробежным органом. Во-вторых это влияние физико-механических свойств сыпучих удобрений и третья причина большая неточность представления удобрений через дозирующее окно устройства на разбрасывающий диск Установлено, что центробежным дисковым разбрасывателем сыпучих минеральных удобрений присуща естественная неравномерность распределения удобрений по поверхности поля, значительно усиливается сегрегацией частиц удобрений на стадии их полета. Так добиться повышения качества распределения можно за счет существенного уменьшения ширины разбрасывания удобрений каждым отдельным диском, уменьшив его диаметра. С целью улучшения качества рассева удобрений предложено многодисковый устройство для рассева минеральных удобрений по поверхности поля. Предлагается устройство выполнить в виде самостоятельных, функционально независимых модулей. Каждый модуль состоит из трех независимых блоков: емкости для удобрений с 
мешалкой; горизонтального дискового дозатора с калибровочными отверстиями; горизонтальной тарелки разбрасывателя. Каждый из блоков обеспечен индивидуальным электроприводом. Такое исполнение позволяет осуществлять регулирование дозировки удобрений на разбрасывая тарелку и дальности разброса удобрений, путем индивидуальной установки определенного числа оборотов вращения диска дозатора и тарелки разброса удобрений. Данная компоновка не ограничивать их число и место закрепления на раме, а ширина захвата агрегата будет регламентироваться только их количеством и дальностью разброса удобрений каждым индивидуальным блоком. В результате исследований макетного образца дозатора с активным принудительно-порционным дозированием сыпучих минеральных удобрений получена его удовлетворительная работоспособность. Но исследования показали, что величина заполнения отверстий диска зависит от оборотов его вращения и от размерных параметров окон загрузки и выгрузки, а также обочин расположенного в конце загрузочного окна. Бордюр предотвращает сдвигу слоев удобрения отношению друг к другу и поверхности диска, вращает, тем самым улучшая заполнения отверстий удобрениями.

Ключевые слова: минеральные удобрения, диск дозировки, разбрасывающия тарелка, равномерность подачи, обороты, калибровочный отверстие, окно загрузки, окно выгрузки.

\section{Abstract \\ Estimation of dimensional and qualitative parameters of work of the horizontal disk batcher}

\section{N.P.Artiomov, A.D. Kalyuzhny, A.A. Romanashenko, I.A. Kolodyazhny}

The large unevenness of fertilizer sifting by centrifugal spreaders is explained by the following reasons. First, it is a manifestation of the technical features of the spreading of fertilizers by the centrifugal body. The second is the influence of physical and mechanical properties of bulk fertilizers and the third reason is the great inaccuracy of fertilizer supply through the metering window of the device on the spreading disk. It is established that stages of their flight. Thus, it is possible to achieve an improvement in the quality of distribution by significantly reducing the width of fertilizer spread by each individual disk, reducing its diameter. In order to improve the quality of fertilizer sifting, a multi-disc device for mineral fertilizer sieving on the field surface is proposed. It is proposed to make the device in the form of independent, functionally independent modules. Each module consists of three independent blocks: fertilizer tanks with a mixer; horizontal disk dispenser with calibration holes; horizontal spreader plate. Each of the units is equipped with an individual electric drive. This implementation makes it possible to adjust the dosage of fertilizers on the spreading plate and the range of spreading fertilizers, by individually setting a certain number of revolutions of the rotation of the dispenser disk and the spreading plate of fertilizers. This layout does not limit their number and location on the frame, and the width of the capture unit will be governed only by their number and range of fertilizer spread by each individual unit. As a result of researches of the model sample of the batcher with active compulsory-portion dosing of loose mineral fertilizers its satisfactory working capacity is received. But studies have shown that the amount of filling the holes of the disk depends on the speed of its rotation and the dimensional parameters of the loading and unloading windows, as well as the presence of the curb located at the end of the loading window. The curb prevents the fertilizer layers from shifting relative to each other and the surface of the rotating disk, thereby improving the filling of the holes with fertilizer.

Keywords: mineral fertilizers, dosing disk, spreading plate, uniformity of presentation, revolutions, calibration hole, loading window, unloading window.

\section{Бібліографічне посилання/ Bibliography citation: Harvard}

Artiomov, N. P. et al. (2020) 'Estimation of dimensional and qualitative parameters of work of the horizontal disk batcher', Engineering of nature management, (3(17), pp. 76 - 80.

Подано до редакції / Received: 12.09.2020 